Energy Research Journal 2 (2): 38-50, 2011

ISSN 1949-0151

(C) 2011 Science Publications

\title{
The Significance of Deepwater Oil Drilling for the US Energy Security: The Case of the Gulf of Mexico
}

\author{
Hafez Abdo and Matthew Vellacott \\ School of Nottingham Trent, University Burton Street, \\ Nottingham NG1 4BU, UK
}

\begin{abstract}
This study seeks to quantify and model the significance of the deepwater oil development for domestic US energy supplies in the short-term. It explores the significance and potential contribution deepwater oil supply from the Gulf of Mexico $(\mathrm{GoM})$ can make in providing energy security to the US. The output of this research demonstrates the growth in deepwater oil production and how this latter relates to total US oil production over the next 10 years; and therefore the role it can play in providing energy security to the USA. The literature offers commercial and academic debate on this topic. The research model analyses current available data and make sensible assumptions on the likely future growth of deepwater oil production in the GoM based on a number of scenarios. Our results support the high/best case and suggest that deepwater oil from the GoM can significantly provide energy security to the US on the short term. However, on the long term and in order to maintain its energy security, the US needs to develop and use renewable sources of energy.
\end{abstract}

Key words: Deepwater oil, energy, Gulf of Mexico, security

\section{INTRODUCTION}

Domestic US oil production is in decline. A growing majority of oil supply to the US now comes from foreign sources. This creates a situation of energy vulnerability or 'in-security' as the US does not have direct control of its own energy supply. This dynamic is a challenge to the US both politically and economically; politically because the US is a world leader and economically because the US has one of the largest global economies.

One of the most active and controversial global deepwater regions is the Gulf of Mexico (GoM), it has provided consistent oil discoveries in the last decade. Currently there is a surge of interest in the region from global and regional independent oil operators following a flow of major deepwater discoveries between 2007 and 2009 such as the BP 'Tiber' field discovery in 2009. The peak in conventional known oil reserves such as onshore and offshore shallow water has been reached in US territory, but improvements in technology have allowed oil companies to explore further from shore. Deepwater, typically at depths below 1,000 feet has offered oil companies a potential new era of oil exploration and production. Large offshore areas such as off the coast of Brazil, West Africa and the $\mathrm{GoM}$ are at the forefront of this exploration.
With conventional US oil reserves in decline since 1970s (EIA, 2010) and with imports accounting for a growing percentage of US oil consumption, currently at $60 \%$ according to the EIA (2010), many politicians, economists and industry participants believe that opportunity for deepwater oil production so close to home must be exploited. To date, the GoM accounts for over $20 \%$ of producing deepwater wells and shares an even greater percentage of deepwater oil discoveries since 2005; it has 31 projects under construction, split by 14 operators. Deepwater oil production accounts for about $30 \%$ of domestic oil production in the US (EIA, 2009) and (MMS, 2009). However, it is worth mentioning that many discoveries in the GoM over the last 30 years remain undeveloped. Development of these discoveries and similar reservoirs pivots on three 'deepening' challenges, these are: 1) ultra deepwater, Ultra deepwater present's new and fundamental barriers to development. The challenges starts with a severe shortage in drilling rigs capable of reaching new depths below 9,000 feet and tension leg permanent production platforms) remoteness Remote locations disrupt traditional methods of development. Remoteness from existing platforms makes this cost prohibitive and therefore new infrastructure is needed and 3) high pressure, high temperature oil reservoirs High pressure,

Corresponding Author: Hafez Abdo, School Nottingham Trent University Burton Street Nottingham NG1 4BU UK, Tel: 0044115 8486098, Fax: 00441158484707 
high temperature fields in ultra deep locations challenges the entire range of subsea product solutions and technology available. High pressure, high temperature changes the design and stress toleration of each product.

Up until 2010 political opinion supported deepwater development both to secure further access to oil resources as a means of strengthening national security and therefore lowering the reliance on oil imports. The drivers and barriers to deepwater oil exploration have been brought to life in 2010 by two events. The first, on 31st March 2010 US President Barack Obama announcement possible policy changes to allow offshore oil drilling off the East coast of Virginia and potentially a wider area including further exploration of the GoM. The second event, the BP operated, Transocean owned rig explosion and subsequent oil leak on the $20^{\text {th }}$ April 2010 has highlighted the reality of technology gaps and has drawn huge media attention to its threat to the local environment.

This paper focuses on the significance of deepwater oil in the GoM in how much it can contribute to US domestic oil supply over the next 10 years and therefore contribute to energy security in the US. It explores the ongoing debate on how far deepwater can go to move the needle on oil supply and the US's reliance on imports. It considers how realistic the deepwater opportunity is and what will the speed of development be in the near term. In support of these questions, the literature review explores the current changing dynamics of the political, economical, social and technological (PEST) influences on development of the GoM.

The literature review: Political, economical, social and technological factors all have an influence on the future significance of deepwater oil. Political factors ultimately decide the necessity of deepwater oil in contributing to the US's energy security. Such decisions are usually driven by national security needs but also closely tied to public opinion and environmental and social sentiment. Economical factors make deepwater development either attractive or cost prohibitive depending on a number of variables. Political decisions and economical factors are dependent on social trends or consumer behaviour including demographics and public opinion on oil usage compared to cleaner energy sources. Technological factors make deepwater exploration and development possible and will have a direct impact on economics, political and social opinions as highlighted by the recent BP oil disaster.

This literature review follows the guidelines of generic industry models to assess the attractiveness and likely potential of deepwater oil including a PEST analysis and Michael Porter's five forces. Typically, Porter's five forces are used by businesses to assess how attractive an industry is for them at a particular moment in time. Porter's five forces are: Suppliers, buyers, substitutes, new entrants and the competitive rivalry within an industry; each factor is dependent on the other. The three factors important to the context of this research questions and objectives are suppliers, buyers and substitutes.

The US energy security position: Vulnerability to oil supply interruptions poses serious threats to the US economy and the life-style of its citizens (Alm, 1981). In this regard, Hirsch (1987) points out that what is needed is an adequate level of national energy security. According to the US Department of Energy, "energy security' means that adequate supplies of energy at reasonable cost and physically available to US consumers from both domestic and foreign sources. It means that the nation is less vulnerable to disruptions in energy supply and that it is better prepared to handle them if they should occur.

A supply interruption by oil suppliers such as OPEC is economically and politically costly. This is an important challenge and leads us to question if vulnerability to 'purpose made' oil supply disruptions is a real driver for the development of domestic production today. Either way, although such restrictions are less common today the potential for supply restriction is seen by many as a threat to countries such as the US that are relying more on imported oil. In fact, oil has been used as a 'weapon' or bargaining tool against its power and stability (Stern, 2006).

Stern, (2006) questions whether the threat is about oil scarcity or in fact about a lack of abundance of oil. These two concerns are very different. While the first suggests an uncontrollable oil supply shortage, the other suggests an inability to access available oil. Stern (2006) dismisses the former, the oil weapon as a threat to US security but he opens a debate on the abundance of oil and its management, particularly by the largest supplier, OPEC. Therefore, the dependence of the US on oil imports and its lack of control on market supply, coupled with increases for oil demand globally drive the US to question this dependence and increase its domestic oil production capacity. With China being expected to overtake the size of the US economy within decades, then surely, the strong position of the US changes and hence increases the threat to its thirst for energy security.

A related point to refer to is the increasing demand outside of the US. The threat of suppliers purposely cutting supply is not the only hazard but in addition 
natural supply shortages or 'a lack of oil abundance' driven by increasing demand for other regions. Growth economies such as China, India and Brazil and other emerging economies such as Indonesia require a greater and growing amount of oil than before. Goose, (2007) points out that the rise of emerging markets changes the supply and demand dynamics. As China, India and the like industrialise and their middle classes grow in wealth, then the global demand for oil and gas rise and for any given level of price, more oil is required. This has exactly the same impact on the price of oil as does reducing supply: the price moves and sharply. This puts the US in a critical position and necessitates searching for domestic oil and gas resources at greater depth of its waters.

Friedland (2010) suggests that the only way the US can get off foreign oil is to stop using oil altogether. He raises an interesting premise that investment into domestic oil supply will make little difference to the US's reliance on foreign imports and therefore challenges Stern's suggestion that abundance of domestically produced oil is a driver for its further exploration and development. Friedland (2010) suggests that oil is running out and that the only real solution to energy shortages is investment and development in new energy sources. The current data from the EIA on US oil imports would suggest Friedland has a strong argument. Furthermore, Reisser (2009) argues that steps towards energy independence such as improved energy efficiency and building fuelefficient vehicles only reduce oil consumption and are unlikely to achieve the goal of US energy independence simply because no meaningful midterm alternatives exist. If Friedland and Reisser are correct, then a switch to an alternative energy source will be the only way to create a sustainable state of energy security; however, this is a long-term, but not immediate, solution to the energy security problem worldwide.

The significance of deepwater oil: Research and development (R\&D) stage of deepwater oil exploration and development was well underway in the US as far back as 1977 when the first drillship was sent out (Simmons, 2003). Academic studies at the time such as Eek (1978) conclude that deepwater drilling is possible, that it is necessary to compensate for declines in conventional hydrocarbons. These early observations highlight how far global understanding of deepwater oil has developed over the last 30 years. Today, the industry moves from $1,000 \mathrm{ft}$ water depth to $10,000 \mathrm{ft}$ and below (MMS, 2009).

Kelly (1998) discusses the concerns surrounding national energy security and highlights deepwater as a significant opportunity for the US to influence the future course of events from both a private sector and government perspective and guarantee that there will be secure access to this important source of energy in the years ahead. The suggestion that deepwater is the possible answer to energy security concerns forms the basis of this paper. Commentators such as Heijen as cited by (Hamilton, 2009) and (Kohl, 2008) simply conclude that the growing investment in deepwater exploration means that easier, conventional oil sources are in decline. Kohl (2008) explains how there is no more easy oil and the subsea industry is "critical to unlocking more oil to meet world supply.' Thurston as cited by (Lynch, 2010) states that "the deep water has been and really truly is potentially the next wave of hydrocarbons into the global energy market. It's hugely important." Leap (2007) stresses that deepwater is one of the few areas where good prospects of major oil finds still remain and these are mainly outside the control of OPEC.

White (2007) explains that within the past 15 years or so, deepwater has evolved from being a "technological frontier to a strategically-important component of the world's oil industry". Due to this history, in relative terms, the deepwater and ultradeepwater regions of the world are still underexplored and hold considerable potential. White (White, 2007) expresses an important transition of deepwater oil from 'technological frontier' to 'strategically important'. It is important to assess how far deepwater has come politically and commercially from a technological frontier to strategically important as the former suggests caution and uncertainty whereas the latter suggests need, commitment and direction.

The relationship between supply and demand and high and low oil prices is highly important to the significance of deepwater oil. The government has a drive to reduce dependence on imports and vulnerability to high oil prices, yet the ultimate driver of oil demand and high oil prices is the consumer. The consumer wants low oil prices. When oil prices are high, the consumer adapts and becomes more efficient. The impact is a fall in prices which in fact translates into a reduction of deepwater drilling, due to its high costs and a resurgence of oil imports (Hirsch, 1987). A related point is that as oil supply lags further behind demand, prices will rise. When prices go up, really hard to reach oil that was previously prohibitively expensive becomes economically feasible to recover (Friedland, 2010).

There is the case to argue that both deepwater oil supply and clean energy can exist together, both playing a part in reducing the US demand for foreign 
oil (Levi et al., 2010). Levi et al (2010) explains how through commitment to clean energy solutions the US could reduce its oil consumption by $30 \%$ between 2007 and 2030 but this is unlikely to cause any abandoning of deepwater oil. Levi et al (2010) base this assumption on that fact that although reduced demand for oil will reduce its price, the price is unlikely to fall to levels below which deepwater oil drilling is no longer profitable. But at what price can deepwater oil be developed at a viable cost? Oil supply is not just about reserves but more importantly, it refers to production rates and deepwater oil is difficult and costly to develop and produce (White, 2007).

Womack (2010) points out that all of Transocean's rigs that can drill at depths greater than 7,500 feet are booked through 2010 Transocean are major global drilling contractor with a significant deepwater drilling fleet, even though more than $40 \%$ of its jack up rig fleet is idle. Therefore, such companies as Transocean, Diamond Offshore Drilling Inc. (DO) and Noble Drilling Services Inc. (NE), which maintain a fleet of deepwater drilling rigs, have been relatively shielded from the recent volatility in oil and gas prices. It is evident that oil companies are investing time and money in deepwater exploration and suggest that the oil companies have little other choice but to explore deepwater opportunities.

Higher oil prices encourage deepwater drilling and development actually highlights an important fact. Supply of deepwater oil appears relatively elastic to fluctuation in oil prices, meaning that a price decrease below a certain level could have a severe knock on effect on deepwater oil supply. However, as many academic studies on the production of oil point out, the oil price influence on deepwater is not as simple as 'high price drives development'. It is a fact that development economics pivot on oil prices and for the right price anything is economical, however, the definition of "not economic under most oil price scenarios differs between the independent smaller operators and the larger oil companies.

Cremer and Salehi-Isfahani (1989) dismiss any forced pressure on oil prices but instead examine the common forces of supply and demand on oil prices. They conclude that they do not think that the price collapses at the time were a result of dislocation of 'a cartel'. Rather it is the result of shifts of the demand and supply curves, which produced an excess supply at a high price. The shift in the supply curve was the result of the development of new reserves, mainly in Mexico and the North Sea, as well as an increase in the absorptive capacity of OPEC Members. The shift in demand has been caused by conservation. But even with high oil prices statistics from the Minerals Management Service (MMS, 2008) shows that development delays and cancellations are still as present as they were back in 2002. In fact, data from Infield (ISOD, 2009) and Petrodata (OCL, 2009) highlights that most recent deepwater developments have been confined to small developments and tiebacks to existing infrastructure.

The Petroleum Economist (PE, 2009) describes deepwater Exploration and Production (E\&P) as a maturing yet expanding frontier. It states that the large number of active deep-water leases, the development of important new discoveries, the growing deepwater infrastructure and new technologies and the onset of ultra-deepwater production are all indicators of this maturing and yet still expanding frontier.

The significance of the opportunity in the GoM: Studies, such as Ekstrand (2007) and Blanchard (2007), have suggested that the GoM may contain about 44 billion barrels of proven reserves on the top of about 50 billion barrels of possible reserves and production from the GoM may peak at about 1.5 million barrels a day in 2010.

Gold (2009) describes how just two decades ago, the GoM was called the 'Dead Sea' by an industry that believed it had already offered up all its big discoveries. But now it is again a centre for petroleum explorers. The Mineral Management Service (MMS), the governing body of the GoM points out those fifteen discoveries in the deepwater GoM in 2008, including five in waters more than 5,000 feet deep, have set the stage for continued production growth. At least five discoveries have been made in the area in 2009. In fact, the GoM has made 68 deepwater and ultra deepwater discoveries since 2005, the result of a deepwater exploration surge at the end of the last century when the US Government and MMS offered a programme of discounts for deepwater leases (MMS, 2009).

In 2008, eleven operators in the GoM have signed long-term contracts to keep new-build rigs drilling in the region for as far ahead as 2015. While key players such as Shell, Chevron and Anadarko have snapped up some of the new build contracts, it is the more recent entrants to the region such as Petrobras that have contracted the most new-build rig. This indicates clearly the opportunity that lies in the GoM that derives these long-term contracts. The fact that there is still oil for the taking is driving major oil companies to come up with new technologies, which are expensive to develop but worth it when crude is riding high. However, even if the new technologies add just a few percentage points to the recovery rate, such gains may add years to global supply and boost the industry's profits.

As can be understood from the above, deepwater oil drilling depicts a significant opportunity in facing 
the peak oil dilemma and its consequences of energy security. With regard to the US energy security, the GoM deepwater oil represents a significant opportunity and present a possible solution for this problem. Recent discoveries in the GoM continue to prove the potential for further supply of oil. It may be not reasonable at this stage to draw a conclusion on what rout the US Government should support, but perhaps the ultimate solution is to support and invest in deepwater oil as far as it provide oil supply to meet part of the growing demand while other energy alternative still more expensive and scarce.

However, due to the immaturity of the sector and the degree of the unknown, the current literature struggles to draw conclusions. It raises further questions on the potential size of the opportunity and how the opportunity will shape the oil and gas industry in the US going forward and how it will impact energy supply going forward and hence provide a state of energy security for the US Key questions arising from the literature review are:

- What is the relationship between discovery, development and production historically and what supply variables drive deepwater oil production

- What is the potential from existing discovered but undeveloped fields in the Gulf of Mexico? When is development of these already discovered fields likely?

- What is the current speed of development of deepwater fields and what are the variables that influence development timelines

Is the Gulf of Mexico capable of producing further discoveries and what does this depend on Certain other issues from the literature should be further investigated such as:

- The relationship between oil price and deepwater discovery and development and

- The attractiveness of deepwater oil development to oil companies and the competiveness of the Gulf of Mexico

Much of the current literature is already outdated by large recent discoveries in 2009. The literature review raises many challenges facing the future development of deepwater oil including the recent social barriers driven by damage to the environment following the recent BP oil spill. In considering the political, economical, social and environmental aspects of the industry, the literature review provides many answers but also raises many questions regarding the future significance of deepwater in the GoM.

\section{MATERIALS AND METHODS}

Methodological approach: Offshore supply modelling is particularly difficult because of the influence of government behaviour and also because of the lags that exist in the response of drilling to economic variables and in response of development and production to successful drilling (Walls, 1994). However, it is a fact that the amount of drilling that takes place is determined by expected discoveries and discoveries are determined by cumulative past drilling.

The objective of this research is to review the current and likely significance of deepwater oil in providing energy security to the USA. To build this picture there are a number of supply and demand variables that were considered by this research. Demand drives supply but supply must be available for any market to achieve balance. Deepwater oil needs will only grow if demand for the deepwater oil grows over other energy sources including conventional oil and renewables. However, deepwater oil will only become significant if its supply is accessible. These drivers reflect both the econometric model and the discovery process model described by Walls (1994), therefore following the hybrid model.

In order to undertake our analysis we applied the 'Econometric Model' explained by Eek (1978) and Walls (1994). The 'Econometric Model' uses historical data to estimate relationships between exploration or development activity, discoveries or production and economic variables such as oil prices and the 'Discovery Process Model' The 'Discovery Process Model' assumes that discovery, development and production will eventually decline in any given region correlated to the amount of exploration in that region over time. We researched the following supply parameters: The potential supply of existing discovered but undeveloped oil fields; Likely speed of development of deepwater fields; Future potential supply - how much deepwater oil supply is possible from the GoM. On the demand side, the following parameters were also researched: a) The influence of oil prices and the strategic intentions of oil companies; b) The attractiveness of deepwater oil fields compared to other available oil sources; and c) Likely supply of other global oil resources.

Based on the above mentioned supply and demand parameters, it will be possible to provide a sensible estimation for on stream production over the next ten years in the GoM and to measure this against the current rate of decline in US conventional oil reserves (assuming full production capacity). This work will help size the contribution that deepwater oil in the GoM 
can make to total US oil supply and to what extent it will help reduce the US's growing reliance on imported oil and hence in meeting the US energy security challenge.

The current potential of deepwater oil in the GoM resides in its undeveloped fields. Will these fields be developed and at what speed? What is the future potential of the GoM? How much has been explored yet and how much remains to be explored? Again, what is the likely timeline for development? Answering these questions should provide an adequate answer to a main question raised by this research which is how significant is the contribution of the deepwater oil supply from the GoM to the state of the US's energy security.

In order to forecast the supply of oil in the GoM a second important step will be to predict likely future discoveries. There is not a precise science to forecasting oil. The method will be to review the rate of historic oil exploration activity in the region correlated to historic discoveries. Forecast rig activity can be used as a proxy for future exploration to assume future discoveries. The results will inform a series of scenarios based on a high (best), medium and low (worst) cases for the potential of deepwater supply from the GoM. These scenarios can then be played out to assess the likely impact of total US oil supply and the future reliance on oil imports.

In performing the above tasks, we used different sources of date, these are: secondary data sources on deepwater oil fields in the GoM, these include details of field sizes, discovery dates, development characteristics and likely production rates. Primary interviews (majority telephone) with key industry participants including oil companies, drilling rig operators, subsea contractors/installers, product manufacturers, associations. Use of previous knowledge of the authors gained from an academic experience and from working with a client on a project looking at deepwater opportunities in Brazil for a subsea products manufacturer.

Analysis and discussion: To set the scene, it is worth reviewing historic trends in domestic US oil production over the last 15 years. Deepwater oil production in the GoM grew at an average of 30\% per year (albeit from a small base) between 1995 and 2002, but began to slowly decline between 2002 and 2008 (see Fig. 1). Shallow water production in the GoM and the US's overall production rate (including onshore) is in decline.

Figure 1 shows that deepwater production in the GoM has been flat or in slight decline since a peak in 2002 but sharply increased between 2008 and 2009. It is important to understand the reasons for this to be able to consider development patterns in the future.

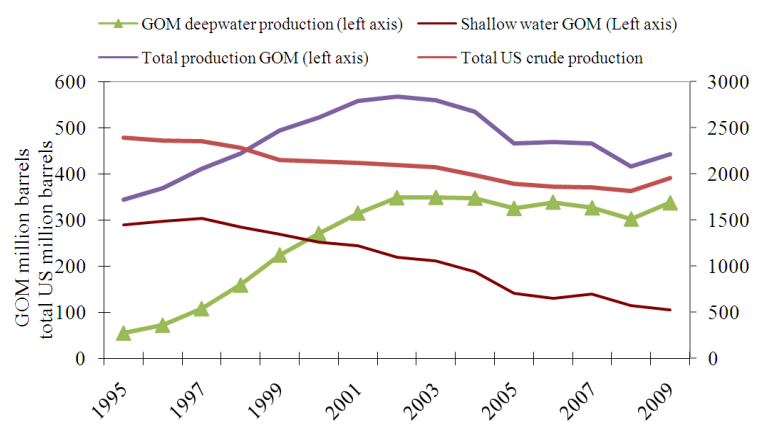

Fig. 1: US and GoM oil production (1995-2009) Source: EIA 2010, Minerals Management Service 2010

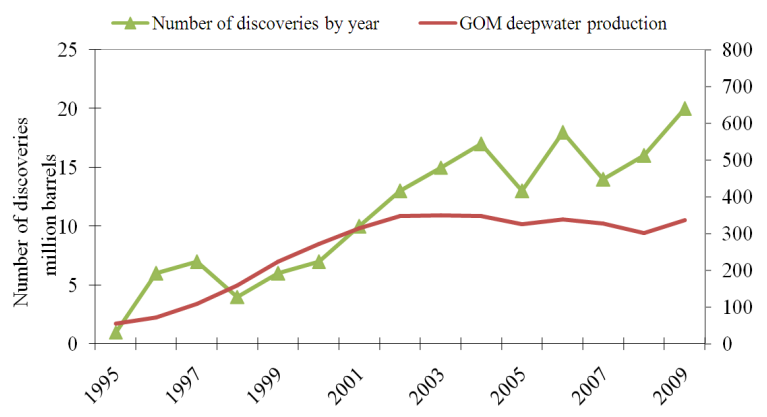

Fig. 2: Oil production and number of deepwater discoveries in the GoM (1995-2009) Source: Subsea Online database 2009, Minerals Management Service, 2009

Should not such an immature growth market be achieving a consistent increase in growth? Is flat to declining production explained by a lack of discoveries or delays in development or something else and what is driving this? At a worst case, perhaps the GoM already reached its peak.

A more confirming figure is Fig. 2, which shows that there has been a steady flow of discoveries in the GoM since 2009 with certain peaks in 2004 and 2006.

Figure 2 provides evidence to suggest that the lull in production growth between 2002 and 2008 is explained somewhat by a flattening in deepwater discoveries from 2004. However, the correlation is weak suggesting that using discovery volume alone, as the data does not give a full picture of the key underlying driver of production. For example, discoveries remain high, above 10 per year after 2004 but production begins to decline. This suggests that extracting new oil supply from total deepwater production would reveal that production is actually in decline. 
Energy Rec. J. 2 (2): 38-50, 2011

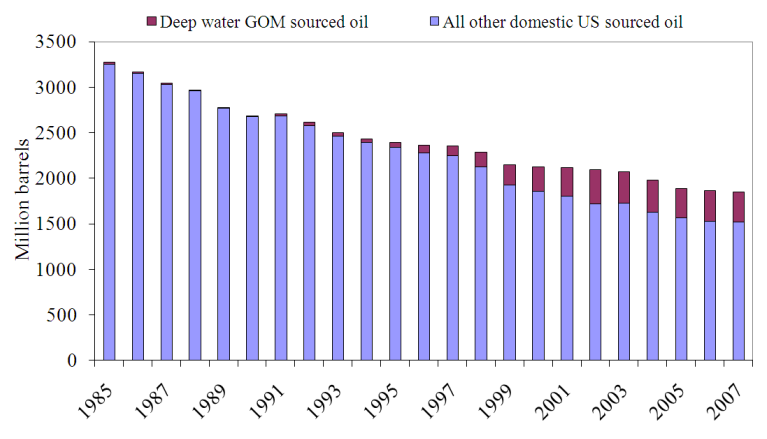

Fig. 3: US oil production and GOM deepwater oil production 1985-2007 Source: EIA 2009, Minerals Management Service 2009

Since 2000, deepwater production in the GoM has slowed the overall US decline from an average of 3\% per year to $2 \%$ (see Fig. 3). Contributing over 300 million barrels of oil to total US oil production, or $18 \%$, deepwater oil already plays a significant role in supplying oil to the US. In order to immediately stop the US oil production decline, deepwater resources in the GoM would need growth of $13 \%$ per year assuming total other reserves continue to decline at $3 \%$ per year In order to stop US production decline by 2015 (five years outlook from 2010), deepwater production would need sustained growth of $10 \%$ per year. However, the promising story is that in the recent years the more exciting potential in the GoM has been in discovery and a pattern of giant deepwater field discoveries but the supply of this is yet to be realised in the form of development and thereafter in production.

Informing the Econometric Model with data related to volume of discoveries, development and production resulted in some correlation between discoveries and developments with discoveries peaks in 2001 and 2004 followed by development peaks in 2003 and 2007. However, the correlation between discovery and development is found to be weak and indirect.

To undertake our analysis, it is essential to discuss a number of supply and demand variables so to form some assumptions to be used in the Econometric Model along with the variables. This analysis will help in deciding the significance of the deepwater oil investment in the GoM to the US energy security at different scenarios.

Existing undeveloped oil fields: To take the relationship between discovery, development and production further it is critical to understand the relative size of deepwater discoveries and developments historically and how reservoir size correlates with production rates. In this sense, it was found that most discoveries, between 1995 and 2009, continue to be small (below 100 million barrels in reserves), there has been a sustained discovery rate of large fields (above 200 million barrels in reserves). This highlights a huge difference between the potential oil supplies of a large sized versus a smaller sized subsea oil fields. It demonstrates that in order to make a significant difference, deepwater oil supply from the GoM will have to provide oil companies with large reservoirs rather than a number of marginal smaller fields. In fact, in recent years, the more exciting potential in the GoM has been in discovery and a pattern of giant deepwater field discoveries but the results or the supply of this is yet to be realised in the form of development and therefore production (see Error! Reference source not found).

It is significantly important to figure out how much 'already discovered' deepwater oil the GoM contains, what is the potential of these already discovered fields and when this potential is likely to be realised in the form of development and production or why it has not been realised? Sandrea and Al Buraiki (2002) suggest that the reason the GoM is so under-developed is that the majority of the fields are not economic under most scenarios. However, a closer review of deep and ultra deep oil fields discovered since 1985 in the GoM by current development status, (see Error! Reference source not found.) Shows that the GoM remains underdeveloped with around a quarter of discovered fields actually producing oil. Around $20 \%$ of fields less than 10 million barrels of oil have been deferred or surrendered. Contrary to Sandrea and Al Buraiki (2002) this is not a majority. In fact, only three fields have been suspended, deferred or surrendered since 2000 and zero since 2004 suggesting that oil companies have found ways to develop these fields economically. The total size of discovered deepwater oil reserves in the GoM amounts to 14.5 billion barrels, which represents $1 \%$ of total world reserves. 4.5 billion barrels of reserves are currently on stream pumping oil. The majorities of field discoveries are either still under construction or have future development plans.

The rate of deepwater conversion, from discovery to production, each year is low but has increased. The annual conversion rate has increased from 6\% in 2006 to $20 \%$ in 2009 The conversion rate of discovered reservoirs to production is well under a quarter although there are signs this is increasing driven by the development completion of large discoveries in 2008 and 2009. Much of this is driven by the completion of significant sized fields discovered in 2000 and 2002 and completed around 2009 including BP's Thunder Horse development and Chevron's / BHP Billiton's Shenzi and Tahiti development (see Error! Reference source not found). Most importantly, new discoveries since 2006 have maintained undeveloped reserve levels over 
the last two years. The sustainability of a $20 \%$ conversion rate will depend on future development completions, size of completion and expected daily production rates.

Likely speed of development: Our analysis, based on data obtained from MMS and other industry sources, reveals that there is clearly a large potential supply of oil, from the GoM, amounting to 14.5 billion barrels in reserves. This would represent $1 \%$ of total global oil reserves. Converting these discovered fields alone would triple the size of deepwater oil production in the GoM. Most of the existing discovered fields have development plans with $10 \%$ of fields cancelled or deferred. In 2009, 20\% of 2008 undeveloped fields were converted to producing. This conversion was compensated for by a number of new discoveries in 2008 and 2009.

In order to clearly understand speed of development and produce a timeline for deepwater oil production going forward we tested historic development timelines for four common types of field characteristics these are: i) size of discoveries; ii) water depth; iii) high pressure/ high temperature (HP/HT) oil reservoirs; and iv) location of oil discoveries. Our testing, which was based on data obtained from Infield subsea online database 2009, resulted in the following outcomes:

- Development time is correlated to size of field up to 100 million barrels with the average development time being four years for the larger fields. However, combined with other variable conditions the development time for a large field can extend to around eight years;

- Development time is somewhat correlated to water depth, but only significantly correlated at extreme ultra deepwater depths below 9,000 feet. The average development time based on the average water depth is five years;

- Development time is correlated to subsea pressure conditions and HP/HT is typically linked to deeper water depths below 3,000 feet. The difference between HP/HT developments and non-HP/HT developments is two years;

- Development time is correlated to the infrastructure need of a deepwater field with an average of two additional years for developments that require topside infrastructure. However, there is little difference between development times of large fields and large remote fields; and

- The highest correlation is between large fields and water depth, followed by large fields in remote locations requiring new infrastructure (typically a floating production and storage platform).

Future potential of the GoM: Excluding the 2010 BP oil spill in the GoM and subsequent bans on development, 24 projects were due for completion in 2010 amounting to a total reserve access of 1.77 billion barrels and an estimated daily production rate of 404 thousand barrels per day, or 149 million barrels per year. If all of these projects completed that would increase the total size of production in the GoM by $50 \%$. The majority of field sizes are between 10 million and 200 million barrels, discovered between 2002 and 2007. In order for deepwater GoM production to make a sustained difference it would be critical to discover more of the larger fields. Clearly, it is not the amount of discoveries that oil companies are interested in; but the size of discoveries, potential production and flow rate. Water depth is the key growing characteristic of new large subsea fields but other characteristics such as remoteness are equally showing double-digit growth. This is important as an indicator for the types of subsea oil field discoveries going forward and the likely development timelines. Using a three-year rolling average since 1998, we noticed that smaller discoveries have been growing at an average of $14 \%$ per year. Depth is a key new characteristic for smaller fields although other characteristic trends are less important.

Studying data from the Minerals Management Service (MMS, 2008) and Infield subsea online database (Leap, 2009) reveals that there is a clear difference between the locations of current development projects versus the concentration of active leases in the GoM. BP's Tiber discovery in 2009 and other significant recent discoveries and developments such as Petrobras's Cascade and Chinook development have all been concentrated in the most unexplored area of the GoM - The 'Lower Tertiary' (see Map 1). The Cascade / Chinook development offers a reserve of 260 million barrels and an annual likely production rate of 18.3 million barrels. There is a clear difference in water depth in the Lower Tertiary, which offers leases consistently at depths below 5,000ft.

The "Lower Tertiary" exposes oil companies to ultra deepwater and has only been lightly explored compared to other areas of the GoM. In 2009, BP made a large discovery in the area and many observers foresee this area as where future attention and investment will be made. Using the same above sources, as for Map 1, suggest that the trend in deepwater leases by water depth in the GoM exploration and development is likely to be in ultra deepwater. Recent discoveries in ultra deepwater suggest a strong possibility of further large discoveries, of more than 200 million barrels of oil in reserves. 
Our analysis of future potential of the GoM resulted in a number of points, these are:

- The clear majority of deep and ultra deepwater discoveries have concentrated around the Green Canyon and Mississippi Canyon since 2000;

- By volume, the Mississippi Canyon continues to provide deepwater discoveries although most are smaller discoveries;

- The Lower Tertiary, including areas such as Keathley Canyon, Walker Ridge and Alaminos Canyon amount to over $80 \%$ of discoveries by size making this a lucrative area for oil companies;

- Green Canyon discoveries appear to be slowing down although the trend is slight;

- Large discoveries and recent discoveries are somewhat correlated to discoveries in ultra deepwater typically in the lightly explored Lower Tertiary area of the GoM;

- Large discoveries in the GoM have been growing at an average of $12 \%$ since 1998 or $14-16 \%$ when in deeper waters or remote locations; and

- Smaller discoveries have grown at an average rate of $14 \%$ since 1998 but trends are not highly correlated with new subsea field characteristics

But will oil companies continue to explore deepwater and will they increase investment in deepwater exploration and development and what will attract them to do so? How do the future drivers compare to the drivers raised and discussed in the literature review? Why the GoM versus other deepwater regions? In order to provide answers to these queries, our analysis will extend at this stage to discuss the impact of the oil price on deepwater oil drilling; the attractiveness of deepwater oil fields; and the competitiveness of the GoM.

The impact of oil prices on deepwater oil drilling: Our first task here is to examine the historic relationship between discovery, development and oil prices; this is to assess how strong influence oil price fluctuations have on deepwater oil exploration and development. Our analysis shows that the search for deepwater oil is not necessarily correlated to oil prices. The literature review points out that deepwater oil is expensive to be developed and produced and much depends on the economic and strategic intentions of oil companies. Oil companies need to be persuaded to firstly search for oil and secondly to develop it. In general, high oil prices lead to high development activity and vice- versa. However, this is not a new fact in the oil and gas industry. Our previous research (Abdo, 2010) shows that higher oil prices motivate development and production activities but not exploration or appraisal for oil and gas. When oil prices are low, oil companies search for oil and gas reserves to build up a portfolio of proven fields and when oil prices increase these companies develop the discovered proved fields. Interviews with a number of key industry experts support our claim.

The significance and competitiveness of deepwater oil drilling in the GoM to the US energy security: In the near to medium-term oil remains number one guaranteed source of energy and its importance cannot be compromised. Much of the debate in the literature supports the fact that the shrinking capacity of conventional US oil production and the increasing dependence on imports will continue to drive exploration and development in the deepwater of the GoM (see (Mackenzie, 2010)). To date, deepwater oil represents $9 \%$ of total US oil consumption, a share that has steadily increased since the 1980 s but flat since 2002 (see Fig. 3). Taking into account the growing reliance on imports and based on our analysis it is safe to state that this flat share of $9 \%$ since 2002 is clearly because of supply challenges rather than lack of demand.

Although, shallow water discoveries in the GoM continue to outnumber deepwater discoveries, the average size of deepwater discoveries is significantly larger than shallow water (see Table 1).

A closer look at oil fields in the GoM by size of reserves shows that shallow water has similar average daily production rates to smaller deepwater oil fields below 100 million barrels in reserves. This is where scale becomes important for oil companies as the more producing fields and deepwater infrastructure a company has in an area the less it cost to add wells and expand development. However, it is the giant fields, above 100 million barrels in reserves, which offer significant long-term daily revenue contribution (see Error! Reference source not found.).

It is the production and oil flow rates which make an oil development worthwhile and attractive. Flow rates in the GoM need to be competitive with other conventional oil sources and other global deepwater regions in order to attract the attention of the major global oil companies. Deepwater flow rates prove challenging and unpredictable as explained in the literature review; this makes investment in deepwater oil risky and complicated. However, the potential production rates of the giant deepwater fields (assuming optimised design of the field and behaviour of the flowing oil) can be very attractive. Recent data suggests that deepwater will provide oil companies more daily revenue opportunity than shallow water (see (MMS, 2008)). 
The GoM has led drilling success by number of discoveries over recent years compared to other deepwater regions and has proved competitive by size of discoveries, although slightly below West Africa and Latin America by total oil barrels discovered. Drilling success rates is a key measurement for oil companies in deciding where to invest their resources. The average production rate per day of discovered deepwater fields in the GoM is well below that of Latin America and West Africa due to the higher number of smaller discoveries in the GoM, although BP's Thunder Horse discovery in the GoM, as an example, offers leading production rates alongside Brazil's major TUPI discovery in 2008. However, by number, frequency and size of discoveries and attractive daily production rates, compared to conventional shallow water fields, the GoM would seem a realistic and high priority for major oil companies.

Furthermore, on top of the production efficiency of the GoM fields, it is commercial, fiscal and political reasons that make the region stand out as an attractive future investment in deepwater oil opportunities. Latin America, although offering significantly higher production rates of about $70 \%+$, is controlled by national oil companies, such as Petrobras. This severely limits the freedom and opportunity of other international oil companies. The GoM is a commercially open playing field for both international and local oil companies making it stand out as an attractive region to be invested in.

Research outcomes: From the above analysis, we obtained a number of key variables and assumptions to feed into the Econometric Driven Forecast Model, these are:

- Oil companies plan to develop at least $90 \%$ of existing deepwater subsea fields in the GoM. The other $10 \%$ of discoveries, typically small, have the potential to be deferred, suspended or cancelled.

- Currently, there are 32 projects under development, amounting to a total of 1.8 billion barrels in reserves and set for completion before 2020 .

- There are 76 discoveries amounting to $7.3 \mathrm{bn}$ barrels of oil in reserves planned, probable and or possible with completion dates set before 2020 .

- Total discoveries have been increasing at a rate of 13\% per year since 1998.

- Large discoveries, above 100 million barrels in reserves, have been increasing at a rate of $12 \%$ per year since 1998 and $14-16 \%$ per year when correlated with water depth and remoteness of the location from existing infrastructure.
- Discovery sizes vary each year, but the average change since 2002 is $4 \%$.

- Average development times susceptible to increases for larger fields driven by extreme water depth, Hp/HT oil conditions and remote locations. A combination of these complications can add up to three years to larger field developments of above 100 million barrels in reserves.

Also, further key variables and assumptions are taken from the analysis to inform a Discovery Driven Forecast Model, these are:

- Heavily occupied regions of the Green Canyon and the Mississippi Canyon indicate a slight slowdown in the frequency of discoveries over the last 3 years, although the economy may play a part

- Demand for leases is switching away from these heavily occupied areas of the GoM and is focused on the 'Lower Tertiary' region

- The Lower Tertiary region is lightly explored, but has produced recent large discoveries above 200 million barrels

Based on the supply and demand variables, discussed above, it is possible to estimate the likely potential size and therefore significance of deepwater oil production in the GoM using sensible assumptions. However, the future of deepwater oil exploration and development is dependent on other external factors, such as the global economy and governmental regulations. Therefore, these estimates will be directional rather than exact. In order to understand the various possible outcomes rather than commit to one directional view, the above set of assumptions and variables assumptions are used to create forecast scenarios based on low, medium and high cases.

\section{CONCLUSION}

After we reviewed the literature, analysed and discussed our data we can conclude that without further increases in deepwater production, the reliance of the US on oil imports would increase to $74 \%$ of total required oil, a jump of $14 \%$ from the current $60 \%$ reliance on oil imports. However, assuming the optimistic high case scenario of further deepwater discoveries and development the reliance on oil imports could be reduced by $18-42 \%$ by 2020 . The medium case view would reduce reliance on oil imports by $13 \%$ to $47 \%$ by 2020 . 


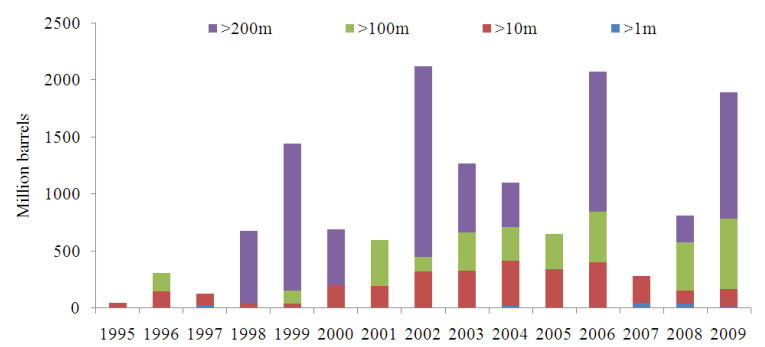

Fig. 4: Deepwater oil discoveries in the GoM by size (range) of discovery, 2000-2009 Source: Infield subsea online database, 2009

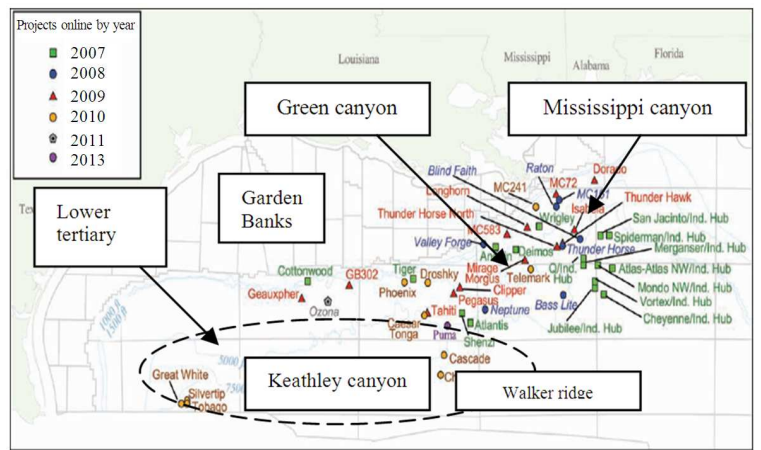

Fig. 5: Current deepwater oil projects in the GoM by year and location, 2008 Source: Minerals Management Service, Deepwater Gulf of Mexico 2008: America's Offshore Energy Future

The low case scenario would reduce imports by $3-58 \%$ by 2020 . The difference between no further increase in oil production in the GoM versus the high case scenario that would provide a $3 \%$ per year increase in total US domestic oil production is demonstrated in Fig. 7 and 8: US oil consumption by source 2010-2020, assuming no further increase in US domestic production and assuming a constant level of demand. Figure 7 depicts US oil consumption by source 2010-2020, assuming high/best-case scenario growth in the GoM to contribute to an increase US domestic production and assuming a constant level of demand. Figure 8: US oil consumption by source 2010-2020, assuming no further increase in US domestic production and assuming a constant level of demand depicts US oil consumption by source 20102020, assuming no further increase in US domestic production and assuming a constant level of demand.

If the GoM realises all of its existing discovered fields in the estimated speed of development timeline it will be able to reserve the growing dependence on imports until 2015 when production will return to a slow decline. However, it will not return to levels of $60 \%$ reliance on oil imports until around 2020.

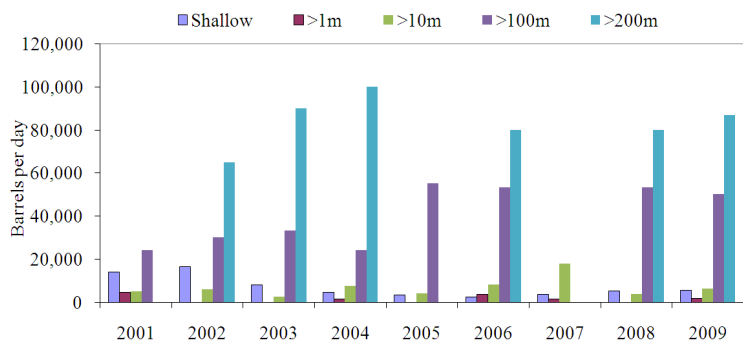

Fig. 6: Deepwater vs. shallow water average daily production rates by reservoir range in the GoM, 2001-2009 Source: Based on data extracted from the Infield subsea online database, 2009

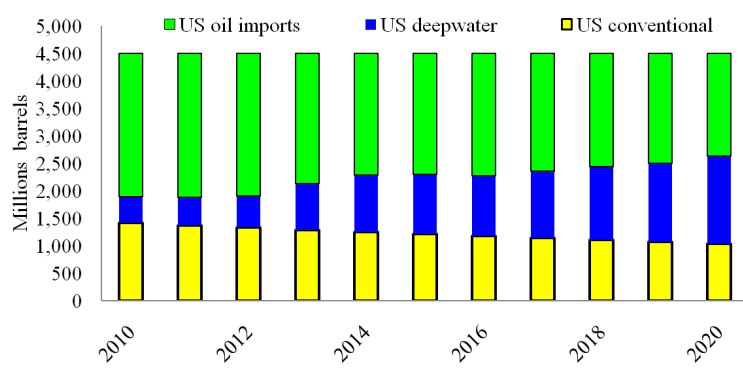

Fig. 7: US oil consumption by source 2010-2020, assuming high / best case scenario Source: Author's own

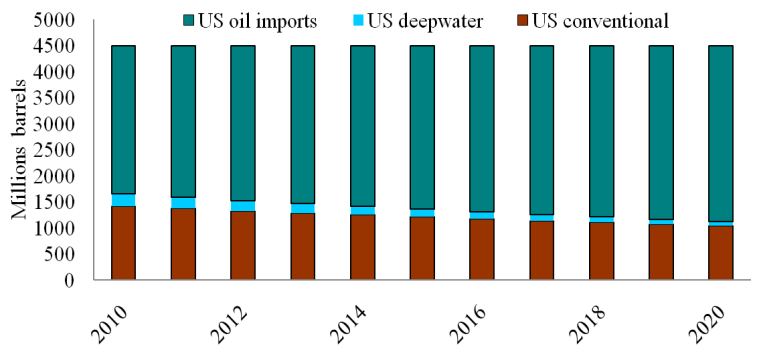

Fig. 8: US oil consumption by source 2010-2020, assuming no further increase in US domestic production and assuming a constant level of demand Source: Author's own

Due to the current situation in the GoM following the BP oil spill in 2010, it is worth demonstrating the forecast picture based on assumed delays as the US reacts to current safety and development regulation for deepwater oil drilling. It is sensible to factor in a oneyear delay for regulation to change and therefore further deepwater drilling to continue. Also, it is sensible to add a further year delay for each development as it is forced to adapt to the new regulation. Factoring in the delays, post the $2010 \mathrm{BP}$ oil spill, results in that import 
could easily grow to around $63 \%$ of total US oil consumption in 2010, assuming constant consumption levels. Deepwater is unlikely to make an impact until 2012 and large discoveries after 2010 are unlikely to have an impact before 2019.

Even an optimistic case in the GoM, as constructed by this paper, is unlikely to shift the US's dependence on foreign oil significantly. The US will eventually return to a period of production decline once discoveries in the Lower Tertiary slow down. Therefore, the bigger picture objective in the US will be continued investment in cleaner, renewable energy for political, economical and environmental reasons. At the same time, deepwater oil is readily available, with potential from already existing developments. In addition, recent huge discoveries have proved the likelihood that more discoveries are within reach. Deepwater oil in the GoM can significantly reduce reliance on oil imports for the short-term. The overall potential is of course unknown but the recent large discoveries encourage oil companies to influence and search for new sources of oil within US territories and continue to lobby the Government to allow drilling of these resources. Deepwater oil in the GoM is not the answer to cheap oil resources as it is expensive to develop. However, it can reduce the US's and global vulnerability to oil price hikes driven by a recovering global economy and growth from China and other emerging markets.

Figure 8 highlights that if the same level of oil consumption is assumed between 2010 and 2020 and no further increase in US oil production is made over the period then the US will increase its reliance on oil imports to over $70 \%$ by 2020 . This demonstrates the concern that the current Government and future US Governments will have on energy security, whether it be for political/defense or economical reasons. With no mass-market alternative on the near-term horizon, deepwater oil development remains attractive to the US with a possible result being a significant decrease in oil imports to below $50 \%$. In addition, importantly it should also be noted that this potential growth in deepwater production would support and provide renewed hope to what has become a dying economy in the US as onshore and shallow water resources dry up. On the other hand, deepwater oil in the GoM would appear a short-term and unsustainable solution to dependence on imported oil and the only way to cease the reliance on foreign oil would be by depending on a cleaner, renewable energy, sourced from domestic resources. Further key takeaways from this research are provided.

This research paper has touched on the significance of the deepwater oil drilling from the Gulf of Mexico on the US energy security. It provides possible solution to the US energy security, but this is only on a shortterm. Further research is required to explore the significance of the renewable sources of energy on the US energy security on both short and longer-terms; this could be the topic of our next research paper.

\section{REFERENCES}

Abdo, H., 2010. Exploring the Rationales for the UK petroleum tax relaxation. Lambert Academic Publishing, Berlin.

Alm, A.L., 1981. Energy supply interruptions and national security. Sci., New Series, 1379-1385. DOI: $10.1126 /$ science.211.4489.1379

Blanchard, R., 2007. Oil dreams in the gulf of Mexico. Association for the Peak Study of Oil and Gas, USA.

Cremer, J. and D. Salehi-Isfahani, 1989. The rise and fall of oil prices: A competitive view. Ann. Écon. Stat., 1516: 427-454.

Eek, W., 1978. The challenge of producing oil and gas in deep water, philosophical transactions of the royal society of London. Series Mathematical Phys. Sci., 21: 113-124.

EIA, 2009. How dependent are we on foreign oil? Energy Information Administration.

EIA, 2010. Petroleum, U.S data. Energy Information Administration.

Ekstrand, R., 2007. Certified shareholder report of registered management investment companies.

Friedland, J., 2010. Peak Oil: The cause of ultradeepwater drilling. The Political Climate.

Gold, R., 2009. BP's big oil find cements gulf's revival. Wall Street J.

Goose, P., 2007. The Economics of oil. Part 1: Supply and Demand Curves, The Oil Drum.

Hamilton, D., 2009. Companies going into deeper waters in pursuit of potentially huge oil returns, The Herald Scotland.

Hirsch, R.L., 1987. Impending united states energy crisis. Sci. New Series, 235: 1467-1473. DOI: 10.1126/science.235.4795.1467

ISOD, 2009. Infield. Subsea Online Database.

Kelly, P., 1998. Deepwater offshore oil development: opportunities and challenges.

Kohl, K., 2008. World oil supply hinges on unlocking the subsea industry. Energy and Capital.

Leap, P.R., 2007. \$100 oil prospect drives deepwater. Oil Services Boom.

Levi, M.A., I.W.H. Parry, A. Pearl and D. Weiss, 2010. Reducing US oil consumption. Council on Foreign Relations. 
Lynch, D., 2010. Deepwater oil fields are a final frontier. USA Today.

Mackenzie, K., 2010. A new era for GoM deepwater oil, and what it says about the majors' strategy. Energy Source.

MMS, 2008. America's offshore energy future. Minerals Management Service, Department of the Interior.

MMS, 2009. Deepwater Gulf of Mexico. Minerals Management Service, Department of the Interior.

OCL, 2009. ODS-Petrodata. Offshore Construction Locator.

PE, 2009. US Gulf of Mexico yields deep-water oil rewards for risk-averse explorers. PetroleumEconomist.

Reisser, W., 2009. The US cannot drill its way out of energy dependence. The Guardian Online.
Sandrea, I. and Al Buraiki, O., 2002. Future of deepwater, Middle East hydrocarbon supplies. Oil Gas J.

Simmons, M., 2003. The urgency of delivering deepwater oil. Society of Petroleum Engineers, Business and Technology.

Stern, R., 2006. Oil market power and united states national security. Nat. Acad. Sci. USA., 103: 16501655. DOI: $10.1073 /$ pnas.0503705102

Walls, M.A., 1994. Using a 'Hybrid' approach to model oil and gas supply: A case study of the gulf of mexico outer continental shelf. Land Econ., 70: 1-19.

White, G., 2007. Does deepwater oil discovery disprove the peak oil theory? Fleet Street Invest.

Womack, J., 2010. Ultra-deepwater drilling likely to remain profitable. The Wall Street J. 